\title{
Eco-Friendly Spray Deposition of Perovskite Films on Macroscale Textured Surfaces
}

An innovative sequential eco-friendly spray coating (SEF-SC) technique is developed to uniformly deposit metal halide perovskite films on macroscale textured surfaces, such as textured crystalline-silicon wafers. Contrasting with previous work on spray-coated perovskite solar cells, the method presented in this work completely avoids the use of toxic and dangerous solvents. Both $\mathrm{MAPbl}_{3}$ and $\mathrm{CsFAMAPbl}{ }_{3-x} \mathrm{Br}_{x}$ perovskite films deposited by SEF-SC show excellent optoelectronic properties and no phase segregation, even when synthesized in ambient conditions. Uniform perovskite coatings are obtained on textured-silicon heterojunction solar cells underlining the promise of this method, which holds the potential for scalable wet processing of perovskites on rough substrates, such as for low-cost perovskite/silicon tandem solar cell fabrication.

In the last decade, metal halide perovskites found successful application as photovoltaic absorber layer in solar cells, nowadays resulting in power conversion efficiencies (PCEs) above $25 \%$ for lab-scale devices. ${ }^{[1]}$ Moreover, the recent coupling of perovskite solar cells with silicon solar cell technology enabled already the realization of monolithic tandem devices with PCEs above $28 \%{ }^{[1]}$ promising a high-end entry of perovskite technology into the mainstream photovoltaics (PV) market.

In the monolithic tandem configuration, also referred as two-terminal (2T) tandem, the perovskite solar cells (PSCs)

S. Sansoni, Dr. F. Lamberti, Prof. M. Meneghetti

Department of Chemical Sciences and UdR INSTM Padova University of Padova

Via Marzolo 1, 35131 Padova, Italy

E-mail: simone.sansoni@phd.unipd.it

Dr. M. De Bastiani, Dr. E. Aydin, E. Ugur, Dr. F. H. Isikgor, A. Al-Zahrani, Prof. F. Laquai, Prof. S. De Wolf

King Abdullah University of Science and Technology (KAUST) KAUST Solar Center (KSC)

Physical Sciences and Engineering Division (PSE)

Thuwal 23955-6900, Kingdom of Saudi Arabia

E-mail: michele.debastiani@kaust.edu.sa

Prof. M. Meneghetti

Interdepartmental Centre Giorgio Levi Cases for Energy Economics and Technology

University of Padova

Via Marzolo 9, 35131 Padova, Italy

The ORCID identification number(s) for the author(s) of this article can be found under https://doi.org/10.1002/admt.201901009.

DOI: 10.1002/admt.201901009 ible with the use of micron-scale textured substrates. Among 31 solution processing techniques, spin coating is widespread 32 due to its process simplicity, ease of access, and because 33 high-quality polycrystalline perovskite films can be obtained. 34 However, this technique is not suitable for upscaling toward 35 industrialization. Also, considering suggestions for large-scale 36 applications in which spin coating is translated into blade 37 coating, the application of this technique usually results in 38 high material consumption, which is undesirable for a sustain- 39 able low-cost production. Moreover, spin coating the perovskite 40 layer on textured silicon bottom cells represents a challenge by 41 itself which, to date, reportedly led to poor coverage of the films 42 resulting in low-performing tandems. ${ }^{[2,3]} \quad 43$

At present, 2T tandems are mainly realized following two 44 approaches. In the first case, the c-Si bottom cell features a 45 mirror-polished flat front surface to accommodate spin-coated 46 perovskite films. However, this causes reflection losses in the 47 device, which hamper the overall PCE and require additional 48 antireflective coatings or foils. ${ }^{[4]}$ In the second case, the perov- 49 skite is deposited on textured c-Si via hybrid conversion, where 50 the perovskite precursors, lead(II) iodide $\left(\mathrm{PbI}_{2}\right)$ and cesium 51 bromide ( $\mathrm{CsBr})$, are thermally evaporated on the c-Si bottom 52 cell and then converted into perovskite by spin coating the 53 organic ammonium salts (formamidinium iodide/bromide, 54 FAI, and FABr, respectively). ${ }^{[2]}$ In this case, the limiting factor 55 is represented by fine-tuning the conversion process. Overall, 56 both techniques strongly rely on spin coating as a deposition/ 57 conversion method, which still represents a roadblock toward 58 scaling-up for commercialization. Indeed, for successful PV 59 
market entry, the 2T tandems arguably need to meet the contemporary standard size of commercial cells (and modules), which for high-efficiency c-Si solar cells are at present based on 6 in. (pseudo-) squared c-Si wafers. ${ }^{[5]}$ In this communication, we present an innovative method to deposition metal halide perovskite thin films on microscale textured surfaces by using a sequential eco-friendly spray coating (SEF-SC) technique. Contrasting with previously reported studies on spray-coated perovskite solar cells, ${ }^{[6-9]}$ our approach completely avoids the use of hazardous solvents. Spray coating is already an established scalable technique which can be easily adopted for various applications. ${ }^{[10]}$ Here, we adapt the technique for the deposition of both methylammonium lead triiodide $\left(\mathrm{MAPbI}_{3}\right)$ and mixed-cation lead mixed-halide $\left(\mathrm{CsFAMAPbI}_{3-x} \mathrm{Br}_{x}\right)$ perovskites, demonstrating the versatility of the technique and its suitability for the realization of perovskite films on $2 \mathrm{~T}$ tandem devices through bandgap tuning. First, we prepare an eco-friendly ink of $\mathrm{PbI}_{2}$ nanocrystals (NCs) via laser ablation synthesis in solution (LASiS) ${ }^{[11-16]}$ and, after adding $\mathrm{CsBr}$ to the colloidal solution, the $\mathrm{PbI}_{2}-\mathrm{CsBr}$ ink is deposited via spray coating on textured-silicon bottom cells. Finally, we converted the inorganic precursor layer into mixed-cation lead mixed-halide perovskite with another spray coating step, now of the organic precursors (FAI, FABr, and methylammonium bromide (MABr)). The same two-step spray coating method was adopted in the case of $\mathrm{MAPbI}_{3}$, by spraying first the $\mathrm{PbI}_{2} \mathrm{NC}$ ink and then MAI solution. With this protocol, the limiting factors of spin coating are avoided,

without losing the benefits of the solution processing or relying 1 on costly vacuum deposition equipment. This technique is compatible with current industrial PV manufacturing standards, paving the way to a scalable low-cost process required for tandem commercialization.

As a test platform for the SEF-SC technique, we first fabricated silicon heterojunction (SHJ) solar cells from float zone n-type c-Si wafers (Figure 1a). Our SHJ process starts with immersing the raw, as-cut c-Si wafers into an alkaline solution to obtain 7-10 micrometric randomly distributed pyramids as texture at the front and back surfaces. Figure 1b shows the cross-section scanning electron microscopy (SEM) image of the textured surface of the c-Si wafer. We then deposited the intrinsic and doped silicon amorphous layers via plasmaenhanced chemical vapor deposition (PECVD) and later indium tin oxide (ITO) by sputtering to form the passivating heterojunction contacts at front and back, as well as the recombination junction, needed to electrically couple the sub cells in the tandem. ${ }^{[17]}$ To accommodate the $2 \mathrm{~T}$ design, we fabricated the $\mathrm{SHJ}$ in a so-called rear-junction configuration (i.e., electrons are collected at the illuminated side of the device) ${ }^{[18]}$ We then sputtered a layer of nickel oxide $\left(\mathrm{NiO}_{x}\right)$ as hole transport layer (HTL) for the inverted ( $\mathrm{p}-\mathrm{i}-\mathrm{n})$ perovskite top cell onto the sunward ITO layer of the bottom cell, acting as recombination junction. ${ }^{[19]}$ More details about the SHJ fabrication are reported in the experimental session. To fully cover the textured surface of the $\mathrm{NiO}_{x} / \mathrm{SHJ}$ bottom cell with perovskite precursors, we

b)
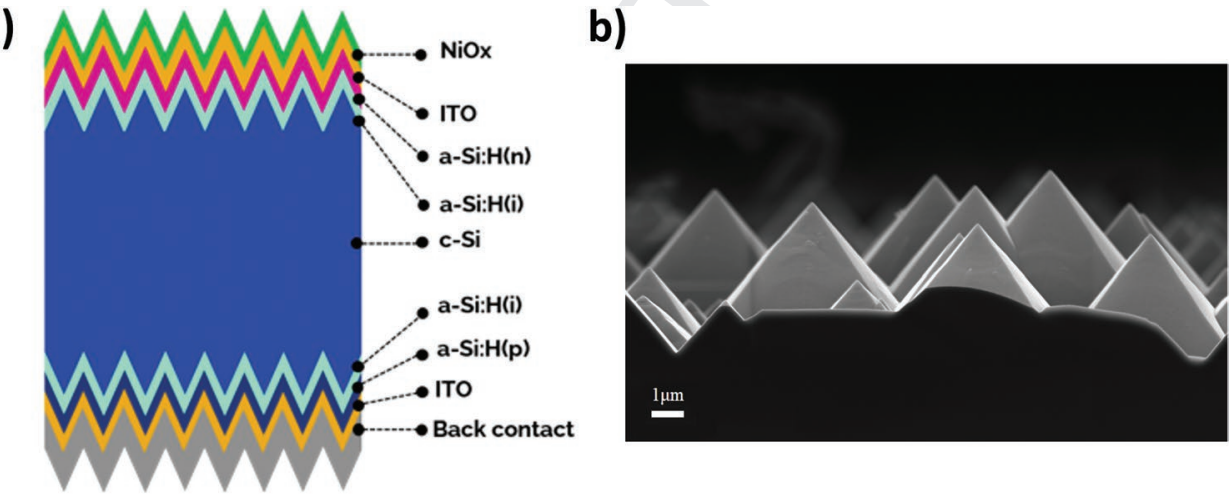
2 3 4 5 6 7 8 9 10 11 12 13 14 15 16 17 18 19 20 21 22 23

c)

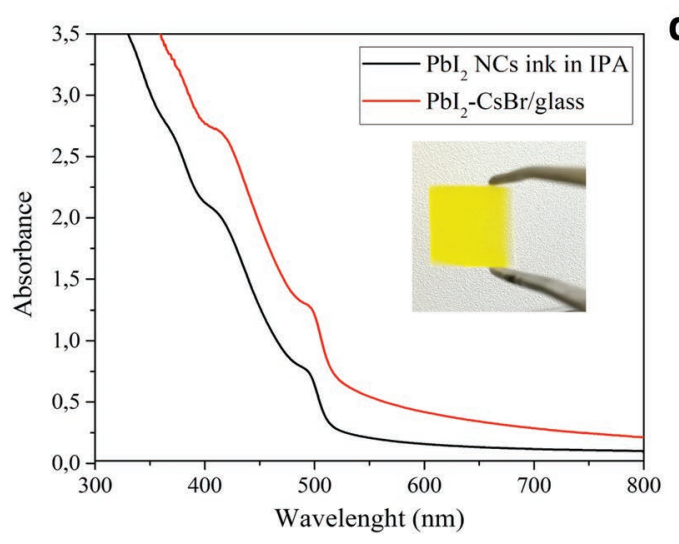

d)

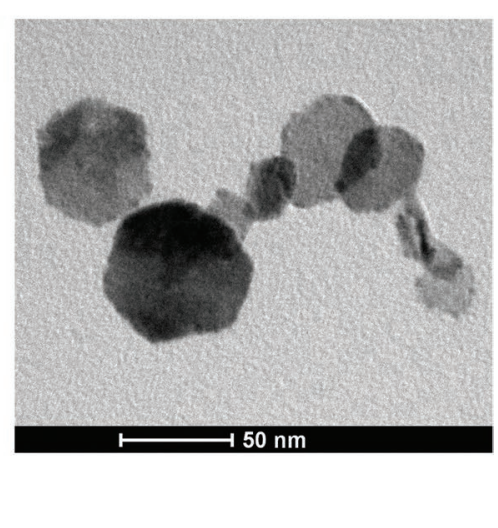

Figure 1. a) Schematic representation (not in scale) of the SHJ bottom cell. b) Cross-sectional SEM image of the textured surface of the randomly distributed silicon pyramids. c) UV-vis absorption spectra of the $\mathrm{Pbl}_{2} \mathrm{NC}$ ink in IPA and the $\mathrm{Pbl}_{2}-\mathrm{CsBr}$ thin film on glass. d) TEM image of the PbI NCs obtained by LASiS in IPA. 
produced $\mathrm{PbI}_{2} \mathrm{NC}$ inks by laser ablation in solution (LASiS). The main advantages of our LASiS approach are the environmental-friendly solvents used in the process, such as alcohols, and absence of ligands or surfactants to stabilize nanoparticles. Indeed, conventional spray coating of perovskite precursors in high-boiling polar solvents, such as dimethylformamide (DMF) and dimethylsulfoxide (DMSO), often hinder the potential of the technique due to the toxicity and hazards related to these solvents. Contrasting with this, we are able to synthesize $\mathrm{PbI}_{2}$ NC inks in low-boiling alcoholic solutions, such as isopropanol (IPA), via laser ablation. The inks are stable over days, requiring only a sonication treatment before spray depositions when stored for long time (Figure S1, Supporting Information). Moreover, the absence of stabilizers in the inks avoids any secondary post-treatment processes, simplifying overall the deposition and cost-efficiency of the process. We refer to the supporting information (Figure S2, Supporting Information) for the experimental setup of LASiS technique and ablation tion spectra of the $\mathrm{PbI}_{2} \mathrm{NC}$ ink and $\mathrm{PbI}_{2}-\mathrm{CsBr}$ thin film deposited on glass. The typical absorption spectrum of $\mathrm{PbI}_{2} \mathrm{NC}$ ink is also preserved, once spray-coated over a substrate, with the typical optical absorption edge at $500 \mathrm{~nm}$. A scattering contribution to the spectrum can be observed for the colloidal solution in the near infrared region since the average dimensions of the $\mathrm{PbI}_{2} \mathrm{NCs}$ are several tens of nm (Figure S3, Supporting Information). The scattering contribution further increases once the $\mathrm{PbI}_{2} \mathrm{NCs}$ are spray coated onto a substrate, since larger structures are formed. Figure $1 \mathrm{~d}$ depicts the transmission electron microscopy (TEM) image of the ablated $\mathrm{PbI}_{2} \mathrm{NCs}$. The ablated NCs appear in the typical hexagonal shape of $\mathrm{PbI}_{2}$ crystals, ${ }^{[20]}$ testifying their crystallinity after synthesis by laser ablation in solution. An average nanocrystals diameter of $51 \pm 9 \mathrm{~nm}$ was estimated from TEM images, in line with the value of $64 \pm 11 \mathrm{~nm}$ obtained from dynamic light scattering (DLS) measurements (Figure S3, Supporting Information). To form details. Figure 1c shows the ultraviolet-visible (UV-vis) absorp-

a compact thin film, we first spray coated $\mathrm{PbI}_{2} \mathrm{NCs}$ and 1 $\mathrm{PbI}_{2}-\mathrm{CsBr}$ inks on top of the textured surface of $\mathrm{SHJ}$ bottom 2 cells, respectively. Then they were respectively converted into 3 $\mathrm{MAPbI}_{3}$ and $\mathrm{CsFAMAPbI}_{3-x} \mathrm{Br}_{x}$ perovskite films by spray 4 coating the solution of the organic precursors, as reported in 5 the experimental section. Figure $2 \mathrm{a}, \mathrm{b}$ respectively shows the 6 top-view and cross-sectional SEM images of the spray-coated 7 $\mathrm{PbI}_{2} \mathrm{NC}$ ink with optimized volume over the textured c-Si sur- 8 faces, which reveals conformal coverage of the c-Si pyramids. 9 Both the tips and the valleys of the pyramids are well covered 10 by spraying $2.0 \mathrm{~mL}$ of $\mathrm{PbI}_{2} \mathrm{NC}$ ink with a concentration of 11 $0.3 \mathrm{mg} \mathrm{mL} \mathrm{mL}^{-1}$ in IPA. Lower solution-loading amounts result 12 in uncovered areas, in particular on the tip of the pyramids 13 (Figure S4, Supporting Information). On the contrary, higher 14 solution-loading films lead to the formation of micrometric- 15 thick bridges between the pyramids (Figure S5, Supporting 16 Information), which complicate subsequent perovskite 17 conversion and could hamper tandem device performance. 18 Similar results were obtained for the $\mathrm{PbI}_{2}-\mathrm{CsBr}$ ink deposition 19 (Figure S6, Supporting Information), where $2.0 \mathrm{~mL}$ solution 20 was confirmed as the best ink volume to spray for obtaining a 21 good conversion and uniform coating of the perovskite film 22 over the textured c-Si surface. As a source of $\mathrm{Cs}^{+}$for the mixed- 23 cation lead mixed-halide perovskite, the inorganic precursor ink 24 was prepared by adding an aqueous solution of $\mathrm{CsBr}$ to the 25 $\mathrm{PbI}_{2}$ NC ink, prepared by laser ablation in IPA. To get fully con- 26 verted $\mathrm{MAPbI}_{3}$ and $\mathrm{CsFAMAPbI}{ }_{3-x} \mathrm{Br}_{x}$ perovskites from $\mathrm{PbI}_{2} 27$ and $\mathrm{PbI}_{2}-\mathrm{CsBr}$ layers, we prepared two different types of 28 organic precursor solutions containing MAI and a mixture of 29 FAI:FABr:MABr in ethylacetate (EA), respectively. For the 30 conversion process, all the samples were annealed at $100{ }^{\circ} \mathrm{C}$ for 31 $10 \mathrm{~min}$ under inert conditions (Ar flux). Images of the spray 32 coating conversion and of our home-made setup can be found 33 in the Supporting Information (Figures S7 and S8, Supporting 34 Information). The SEM micrographs of the best $\mathrm{MAPbI}_{3}$ and 35 $\mathrm{CsFAMAPbI}_{3-x} \mathrm{Br}_{x}$ samples are reported in Figure 2c,d and e,f, 36
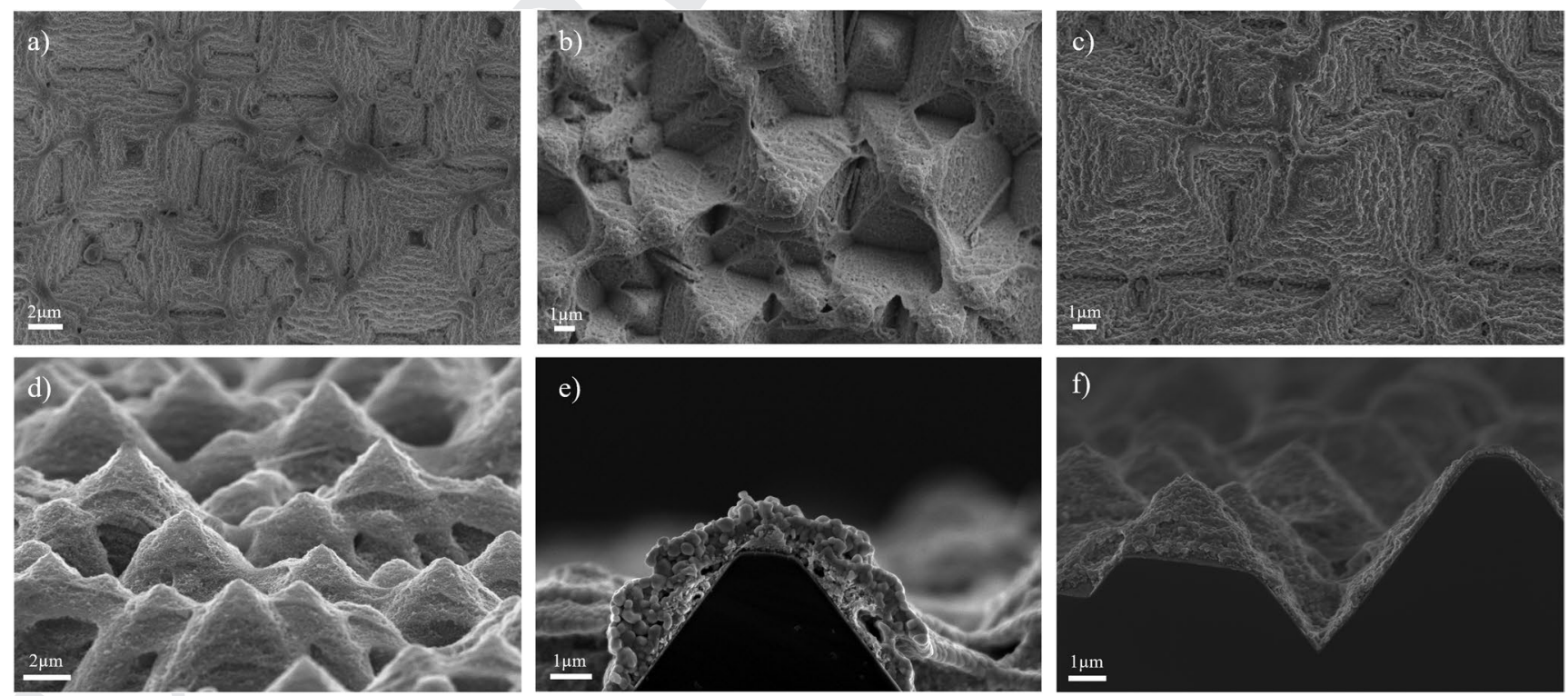

Figure 2. Top-view and cross-section SEM images of the spray-coated films onto the textured silicon bottom cell. a-d) $\mathrm{Pbl}{ }_{2} \mathrm{NC}$ ink, $\mathrm{b}-\mathrm{e}$ ) $\mathrm{MAPbl}_{3}$

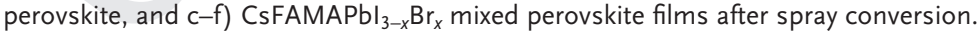

\section{7}


respectively. Both samples show a conformal perovskite layer with well-defined crystals; the conformal coating mimics the texturing of the $\mathrm{SHJ}$ bottom cell. To find the optimal conversion conditions, we changed both the concentration and the volume of the organic precursor solutions sprayed over the $\mathrm{PbI}_{2} / \mathrm{PbI}_{2}-$ $\mathrm{CsBr}$ thin films. The volume seemed not to be a relevant parameter by itself. What turned out to be more critical was to calibrate the ink flow of the spray coater to guarantee that the spray deposition process was complete in just one cycle. One-cycle spraying is important to avoid dissolution and recrystallization of the perovskite crystals, which would otherwise lead to a nonconformal coating on the textured substrate. As expected, at a fixed volume, organic solutions with low concentrations lead to an unconverted $\mathrm{PbI}_{2} / \mathrm{PbI}_{2}-\mathrm{CsBr}$ layer at the perovskite/ $\mathrm{NiO}_{x}$, interface of the top cell in the $2 \mathrm{~T}$ tandem device structure (Figure S9b, Supporting Information). On the contrary, those solutions with higher concentrations resulted in crystallization of the organic precursors onto the perovskite films. Moreover, we found that the concentration of MAI solutions plays a key role in determining the quality of the final perovskite film in the case of $\mathrm{MAPbI}_{3}$. In particular, we synthesized $\mathrm{MAPbI}_{3}$ with bigger grains (up to $700 \mathrm{~nm}$ ) by spraying an over-stoichiometric quantity of MAI over the $\mathrm{PbI}_{2} \mathrm{NCs}$ (Figures S9 and S10, Supporting Information). Despite this, the best $\mathrm{MAPbI}_{3}$ film (Figure 2b-e) was obtained in stoichiometric conditions to get a uniform coating on the textured c-Si substrate without MAI accumulations. For this, a 1:1 molar ratio between $\mathrm{PbI}_{2}$ and MAI was used, by spraying $2.0 \mathrm{~mL}$ of $0.3 \mathrm{mg} \mathrm{mL}-1 \mathrm{PbI}_{2} \mathrm{NC}$ ink in IPA and then converting into perovskite by spraying $1.0 \mathrm{~mL}$ of $0.2 \mathrm{mg} \mathrm{mL} \mathrm{m}^{-1}$ MAI solution in EA. In the case of $\mathrm{CsFAMAPbI}_{3-x} \mathrm{Br}_{x}$ perovskites, good conversion was only obtained in stoichiometric conditions between inorganic and organic precursors. The best mixed-cation lead mixed-halide perovskite film (Figure 2c-f) was obtained by spraying $2.0 \mathrm{~mL}$ of $0.3 \mathrm{mg} \mathrm{mL} \mathrm{mbI}_{2}-\mathrm{CsBr}$ ink and then converting it by spraying $1.0 \mathrm{~mL}$ of $5.6 \mathrm{mg} \mathrm{mL}^{-1}$ FAI-FABr-MABr (10:6:3 molar ratio) solution in IPA diluted 1:50 (v:v) in EA. Samples of the spray-cast, mixed perovskite with increasing thickness are reported in the supporting information (Figure S11, Supporting
Information). All of the spray-coated perovskite films show 1 smaller crystal grains than those reported in literature. ${ }^{[6,8]} \mathrm{We}$ ascribe this to the $\mathrm{PbI}_{2} \mathrm{NC}$ precursor layer, which provides a large amount of perovskite nucleation centers. Moreover, the dissolution and the recrystallization of precursors and perovskite, respectively, are highly hindered using low-boiling volatile solvents for the whole spray coating deposition process. For further structural analysis, we performed X-ray diffraction (XRD) measurements as shown in Figure 3a. Both $\mathrm{MAPbI}_{3}$ and $\mathrm{CsFAMAPbI}_{3-x} \mathrm{Br}_{x}$ films do not present any residual reflections of the $\mathrm{PbI}_{2}$ precursor, suggesting complete conversion into perovskite. To investigate the optical properties of the spraycoated perovskite films, we prepared a specific set of samples on textured silicon wafers covered by $300 \mathrm{~nm}$ of silicon nitride $\left(\mathrm{SiN}_{x}\right)$ deposited via PECVD. The dielectric $\mathrm{SiN}_{x}$ layer is required to isolate the perovskite films from possible electronic interaction with the c-Si wafers. On these substrates, we performed time-resolved photoluminescence (TRPL) spectroscopy with a streak camera to collect the spectral shape and time evolution of the PL at once for $\mathrm{MAPbI}_{3}$ and the CsFAMAPbI ${ }_{3-x} \mathrm{Br}_{x}$ perovskite films. Figure S12 (Supporting Information) shows the 2D pseudocolor graphs for each sample. Additionally, we used a $\mathrm{MAPbI}_{3}$ film spin coated on quartz substrate as a reference sample. Figure $3 \mathrm{~b}$ shows the normalized PL spectra of $\mathrm{MAPbI}_{3}$ (blue), CsFAMAPbI ${ }_{3-x} \mathrm{Br}_{x}$ (orange), and reference spin-coated $\mathrm{MAPbI}_{3}$ (black). Both the spray- and spin-coated $\mathrm{MAPbI}_{3}$ films exhibit emission centered at $770 \mathrm{~nm}$, which is indicative of a bandgap of around $1.61 \mathrm{eV}$, in agreement with $\mathrm{MAPbI}_{3}$ polycrystalline films. ${ }^{[21,22]}$ The mixed perovskite shows a broader and blueshifted emission, centered at $736 \mathrm{~nm}$, indicative of a higher bandgap around $1.68 \mathrm{eV}$. This corresponds to a $\mathrm{Br}^{-}$ratio of about $25 \%$ with respect to $\mathrm{I}^{-}{ }^{-[23]}$ Moreover, the emission is stable even after keeping the $\mathrm{CsFAMAPbI}{ }_{3-x} \mathrm{Br}_{x}$ perovskite sample in ambient conditions for many hours, without evidences of dominant phase segregation (Figure S13, Supporting Information). This is in agreement with previous results from mixed halide perovskites obtained via LASiS. ${ }^{[15,24]}$ Figure $3 c$ shows the PL lifetime of the three samples obtained with a laser excitation at $532 \mathrm{~nm}$ (further details are reported in a)

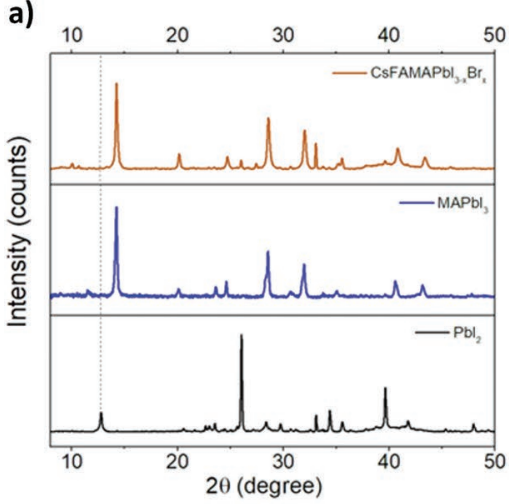

b)

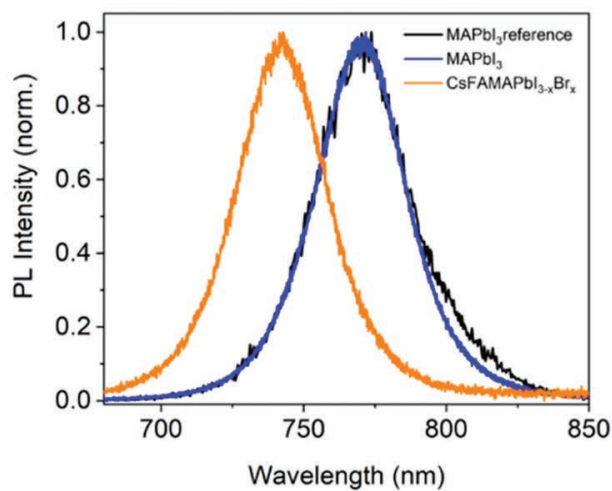

c)

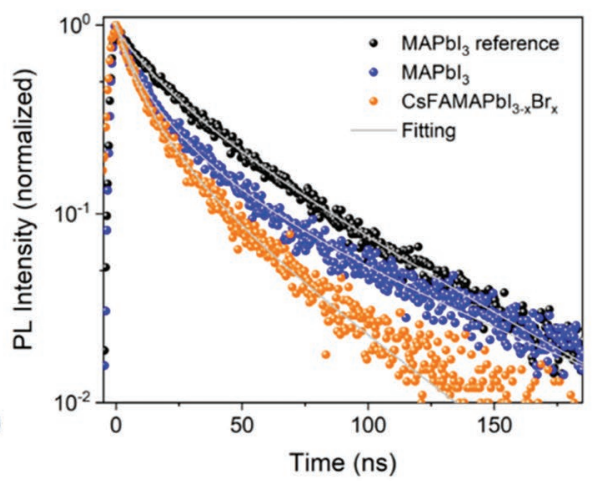

Figure 3. a) XRD diffraction pattern of the $\mathrm{CsFAMAPbl}{ }_{3-x} \mathrm{Br}_{x}$ (orange), $\mathrm{MAPbl}_{3}$ (blue), and spray-coated $\mathrm{Pbl}_{2}$ (black) films. The reflection peaks at $33^{\circ}$ is from the silicon substrate. b) Normalized PL spectra and c) transient PL decay of spin-coated MAPbl ${ }_{3}$ (black), spray-coated MAPbl ${ }_{3}$ (blue), and spraycoated $\mathrm{CsFAMAPbl}_{3-x} \mathrm{Br}_{x}$ (orange) perovskite films on textured silicon. The spin-coated $\mathrm{MAPbl}_{3}$ (black) on quartz substrate is shown as reference. The

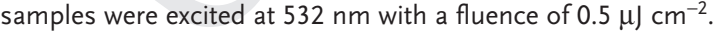
3 4 5 6 7 8 9 
the experimental session). We used a biexponential fit to extrapolate the average PL lifetime $\left(\tau_{\text {avg }}\right)$ from the decay transients. The $\mathrm{MAPbI}_{3}$ films shows a similar transient at later times; on the other hand, the films have PL lifetimes of 21 and $33 \mathrm{~ns}$ for the spray-casted and spin-coated films, respectively. For the $\mathrm{CsFAMAPbI}_{3-x} \mathrm{Br}_{x}$ sample, the PL lifetime is slightly reduced, with a $\tau_{\text {avg }}$ of $17 \mathrm{~ns}$. Although, the mixed cations stabilize the structure and enhances the PL lifetime of the perovskite, increasing the $\mathrm{Br}$ ratio in the structure (wider bandgap) reduces the PL lifetime. This has been attributed mainly to halide segregation under illumination. ${ }^{[25,26]}$ In our case, we did not observe notable halide segregation during measurement for optimized samples. Additionally, we conducted the TRPL measurements for the samples prepared with different volume of precursor solution as discussed before. Parallel to SEM micrographs, mixed-cation lead mixed-halide perovskite made from 1:2 molar ratio between inorganic-organic precursors resulted in a longer lifetime which also proves the better conversion yielding and higher quality of the mixed perovskite film (Figure S14, Supporting Information).

An innovative method is presented to deposit metal halide perovskite thin films on textured surfaces by using a sequential eco-friendly spray coating (SEF-SC) technique. The SEF-SC protocol, avoids the usage of toxic and dangerous solvents, solving an important step of perovskite solar cell technology. Starting from a $\mathrm{PbI}_{2} \mathrm{NC}$ ink made by laser ablation in alcohol, we demonstrate its deposition on textured silicon substrates by spray coating and its conversion into the desired perovskite layer by a second spray step of the organic precursors for obtaining $\mathrm{MAPbI}_{3}$ and $\mathrm{CsFAMAPbI}{ }_{3-x} \mathrm{Br}_{x}$. SEM investigation allowed to optimize the deposition conditions for obtaining a conformal coating of the textured SHJ bottom solar cells. Good perovskite coverage was obtained, with smaller crystal grains than those reported in literature. This result is related to the $\mathrm{PbI}_{2} \mathrm{NC}$ precursor layer and the low-boiling volatile solvents used for the spray coating process. Different conversion conditions and/or perovskite post-treatments could be evaluated to improve the morphology of the films, to decrease the amount of grain boundaries and increase the grain size. ${ }^{[27-32]}$ XRD patterns, testified a complete conversion of precursors into perovskite phases. PL measurements showed a bandgap change for $\mathrm{Br}$ incorporation into $\mathrm{CsFAMAPbI}_{3-x} \mathrm{Br}_{x}$ film, which is important for perovskite-silicon tandem application. The presented new deposition protocol well suits industrial standards and will be interesting for future large-scale tandem fabrication by optimizing also the spray coating of the layers needed for a complete cell.

\section{Experimental Section}

Sequential Eco-Friendly Spray Coating: A sketch of the sequential eco-friendly spray coating (SEF-SC) approach presented in this work for deposition of perovskite thin films over $\mathrm{NiO}_{x} / \mathrm{ITO} /$ textured silicon substrates for silicon-perovskite $2 \mathrm{~T}$ tandem solar cells application is depicted in Figure S8 (Supporting Information). The process was performed by using a home-made spray coating system operating with a nitrogen flow at 3 bar and with an output temperature of $45^{\circ} \mathrm{C}$. The airbrush was controlled by stepper motors regulating the horizontal and vertical steps, with a speed of $0.4 \mathrm{~cm} \mathrm{~s}^{-1}$. The tip $(0.25 \mathrm{~mm}$ nozzle diameter) was located $3 \mathrm{~cm}$ far from the substrates, which were heated at 1 $100{ }^{\circ} \mathrm{C}$ by a hot plate integrated into the spray coater. The optimized ink 2 flow for the first (Figure 2a) and the second step (Figure S8b, Supporting Information) was equal to 0.2 and $0.4 \mathrm{~mL} \mathrm{~min}-1$ respectively. All the perovskite films were deposited under extractor hood (50\% humidity) with an area of $1.5 \times 1.5 \mathrm{~cm}^{2}$. Finally, all the samples underwent thermal annealing for $10 \mathrm{~min}$ at $100{ }^{\circ} \mathrm{C}$ under inert atmosphere (Ar flow).

$\mathrm{Pbl}_{2}$ NC-CsBr Thin Film on Soda-Lime Glass: The precursor thin film 7 reported in Figure $1 \mathrm{c}$ was obtained by spray coating $2.0 \mathrm{~mL}$ of $\mathrm{Pbl}_{2} \mathrm{NC} 8$ ink in IPA $\left(0.3 \mathrm{mg} \mathrm{mL}^{-1}\right)$ mixed with $20 \mu \mathrm{L}$ of $\mathrm{CsBr}$ aqueous solution $\left(0.7 \mathrm{mg} \mathrm{mL} \mathrm{m}^{-1}\right)$ over soda-lime glass $\left(1 \times 1 \mathrm{~cm}^{2}\right)$ substrate, heated at $100{ }^{\circ} \mathrm{C}$ by a hot plate. The $\mathrm{Pbl}_{2} \mathrm{NC}-\mathrm{CsBr}$ ink was sonicated for 5 min before spraying. The spray deposition was performed under extractor hood in ambient condition, with a constant ink flow of $0.3 \mathrm{~mL} \mathrm{~min}{ }^{-1}$.

Steady-State Photoluminescence (SS-PL): SS-PL measurements were 13 performed using a Renishaw InVia micro-Raman instrument, equipped 14 with a CCD detector (100 $\mu \mathrm{m}$ slits) and a piezoelectric xyz scanning 15 stage. A $633 \mathrm{~nm}$ line of He-Ne laser (Renishaw RL63, $13 \mathrm{~mW}$ ) excitation beam with an output power of $1 \mu \mathrm{W}$ was focused on the sample using a 50x objective. A reference of crystalline silicon was used before and after each measurement to account for small (less than 5\%) intensity fluctuations of the laser output. All the measurements were performed in ambient conditions. measurements camera system conducted using a high-resolution streak 22 $532 \mathrm{~nm}$ (HELIOS 532-4-125, Coherent Inc). The excitation beam at 23 perovskite, mounted inside the sealed nitrogen chamber to prevent any 24 changes due to exposure to oxygen and humidity. The associated PL 25 emission was spectrally and temporally resolved using a spectrograph 26 and streak camera system. The data were acquired in photon counting 27 mode using the Streak Camera software (HPDTA) and exported to 28 Origin Pro 2015 for further analysis. All measurements were done at room temperature.

Silicon Bottom Cell Fabrication: SHJ solar cells are realized on floatzone double-side-textured four inches wafers (thickness 250-280 $\mu \mathrm{m}$ ) as defined in the previous study. ${ }^{[33]}$ The wafers are processed in alkaline solution to obtain randomly distributed pyramidal texturing and cleaned in RCA1 and RCA2 solution. Amorphous intrinsic and doped silicon layers are deposited via plasma-enhanced chemical vapor deposition (PECVD, Indeotec Octopus 2). The back contact of the SHJ is realized by sputtering sequentially ITO and $\mathrm{Ag}$ ( 150 and $250 \mathrm{~nm}$, respectively) in the PVD part of the Octopus 2 cluster. To mimic the tandem configuration, an ITO sputtered layer $(25 \mathrm{~nm})$ covered by a sputtered layer of $\mathrm{NiO}_{x}$ $(17 \mathrm{~nm})$ are deposited as the recombination junction and the perovskite hole transport layer (Angstrom EvoVac).

\section{Supporting Information}

Supporting Information is available from the Wiley Online Library or from the author.

\section{Acknowledgements}

The research reported in this publication was supported by funding from King Abdullah University of Science and Technology (KAUST) under award no. OSR-CARF URF/1/3079-33-01 and the project OPERA of the Interdepartmental Centre Giorgio Levi Cases for Energy Economics and Technology, University of Padova.

\section{Conflict of Interest}

The authors declare no conflict of interest. . (15) 18

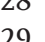
32 33 34 35 35 36 37 38

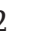
3
4
5 6 6

\section{(10} 17 19 20 1 22

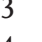

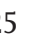

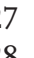




\section{Keywords}

eco-friendly spray deposition, laser ablation, perovskites, textured surfaces

Received: November 11, 2019

Revised: December 9, 2019

Published online:

[1] National Center for Photovoltaics (NCPV), N.N.C.f.P., 2019.

[2] F. Sahli, J. Werner, B. A. Kamino, M. Bräuninger, R. Monnard, B. Paviet-Salomon, L. Barraud, L. Ding, J. J. Diaz Leon, D. Sacchetto, G. Cattaneo, M. Despeisse, M. Boccard, S. Nicolay, Q. Jeangros, B. Niesen, C. Ballif, Nat. Mater. 2018, 17, 820.

[3] J. Werner, F. Sahli, F. Fu, J. J. Diaz Leon, A. Walter, B. A. Kamino, B. Niesen, S. Nicolay, Q. Jeangros, C. Ballif, ACS Energy Lett. 2018, 3, 2052.

[4] Y. Jiang, I. Almansouri, S. Huang, T. Young, Y. Li, Y. Peng, Q. Hou, L. Spiccia, U. Bach, Y. B. Cheng, M. A. Green, A. Ho-Baillie, J. Mater. Chem. C 2016, 4, 5679.

[5] C. Battaglia, A. Cuevas, S. De Wolf, Energy Environ. Sci. 2016, 9, 1552.

[6] J. H. Heo, M. H. Lee, M. H. Jang, S. H. Im, J. Mater. Chem. A 2016, $4,17636$.

[7] Y.-S. Chou, L.-H. Chou, A.-Z. Guo, X.-F. Wang, I. Osaka, C.-G. Wu, C.-L. Liu, ACS Sustainable Chem. Eng. 2019, 7, 14217.

[8] M. Park, W. Cho, G. Lee, S. C. Hong, M. C. Kim, J. Yoon, N. Ahn, M. Choi, Small 2019, 15, 1804005.

[9] S. Uličná, B. Dou, D. H Kim, K. Zhu, J. M. Walls, J. W. Bowers, M. F. A. M. van Hest, ACS Appl. Energy Mater. 2018, 1, 1853.

[10] A. Tiwari, L. Uzun, Advanced Functional Materials, Wiley, Hoboken, N) 2015.

[11] G. Yang, Laser Ablation in Liquids-Principles and Applications in the Preparation of Nanomaterials, Pan Stanford Publishing, Boca Raton, FL 2012.

[12] N. G. Semaltianos, Crit. Rev. Solid State Mater. Sci. 2010, 35, 105.

[13] H. Zeng, X. W. Du, S. C. Singh, S. A. Kulinich, S. Yang, J. He, W. Cai, Adv. Funct. Mater. 2012, 22, 1333.

[14] R. A. Ismail, A. M. Mousa, K. S. Khashan, M. H. Mohsin, M. K. Hamid, J. Mater. Sci.: Mater. Electron. 2016, 27, 10696.

[15] A. Rizzo, F. Lamberti, M. Buonomo, N. Wrachien, L. Torto, N. Lago, S. Sansoni, R. Pilot, M. Prato, N. Michieli, M. Meneghetti,
G. Meneghesso, A. Cester, Sol. Energy Mater. Sol. Cells 2019, 189, 1 43.

[16] V. Amendola, S. Polizzi, M. Meneghetti, J. Phys. Chem. B 2006, 110, 3 7232.

[17] T. G. Allen, J. Bullock, X. Yang, A. Javey, S. De Wolf, Nat. Energy 2019, 4, 914.

[18] A. Descoeudres, Z. C. Holman, L. Barraud, S. Morel, S. De Wolf, C. Ballif, IEEE J. Photovoltaics, 2013, 3, 83.

[19] E. Aydin, J. Troughton, M. De Bastiani, E. Ugur, M. Sajjad, A. Alzahrani, M. Neophytou, U. Schwingenschlögl, F. Laquai, D. Baran, S. De Wolf, ACS Appl. Energy Mater. 2018, 1, 6227.

[20] E. Klein, R. Lesyuk, C. Klinke, Nanoscale 2018, 10, 4442.

[21] V. D'Innocenzo, A. R. Srimath Kandada, M. De Bastiani, M. Gandini, A. Petrozza, J. Am. Chem. Soc. 2014, 136, 17730.

[22] F. H. Isikgor, B. Li, H. Zhu, Q. Xu, J. Ouyang, J. Mater. Chem. A 2016, 4, 12543.

[23] K. A. Bush, K. Frohna, R. Prasanna, R. E. Beal, T. Leijtens, S. A. Swifter, M. D. McGehee, ACS Energy Lett. 2018, 3, 428.

[24] F. Lamberti, L. Litti, M. De Bastiani, R. Sorrentino, M. Gandini, M. Meneghetti, A. Petrozza, Adv. Energy Mater. 2017, 7, 1601703.

[25] M. Jaysankar, B. A. L. Raul, J. Bastos, C. Burgess, C. Weijtens, M. Creatore, T. Aernouts, Y. Kuang, R. Gehlhaar, A. Hadipour J. Poortmans, ACS Energy Lett. 2019, 4, 259.

[26] E. T. Hoke, D. J. Slotcavage, E. R. Dohner, A. R. Bowring, H. I. Karunadasa, M. D. McGehee, Chem. Sci. 2015, 6, 613.

[27] F. Guo, W. He, S. Qiu, C. Wang, X. Liu, K. Forberich, C. J. Brabec, Y. Mai, Adv. Funct. Mater. 2019, 29, 1900964.

[28] Z. Zhou, Z. Wang, Y. Zhou, S. Pang, D. Wang, H. Xu, Z. Liu, N. P. Padture, G. Cui, Angew. Chem., Int. Ed. 2015, 54, 9705.

[29] R. Brenes, D. Guo, A. Osherov, N. K. Noel, C. Eames, E. M. Hutter S. K. Pathak, F. Niroui, R. H. Friend, M. S. Islam, H. J. Snaith, V. Bulović, T. J. Savenije, S. D. Stranks, Joule 2017, 1, 155.

[30] F. Wang, S. Bai, W. Tress, A. Hagfeldt, F. Gao, npj Flexible Electron. 2018, 2, 22.

[31] W. Hou, Y. Xiao, G. Han, C. Qin, L. Xiao, Y. Chang, H. Li, Mater. Res. Bull. 2019, 112, 165.

[32] J. A. Yang, T. Qin, L. Xie, K. Liao, T. Li, F. Hao, J. Mater. Chem. C 2019, 7, 10724.

[33] E. Aydin, M. De Bastiani, X. Yang, M. Sajjad, F. Aljamaan, Y. Smirnov, M. N. Hedhili, W. Liu, T. G. Allen, L. Xu, E. Van Kerschaver, M. Morales-Masis, U. Schwingenschlögl, S. De Wolf, Adv. Funct. Mater. 2019, 29, 1901741.

\section{2} 3 


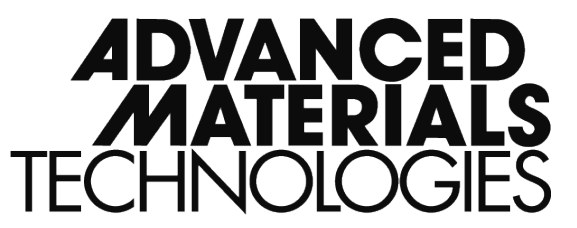

Reprint Order Form

Charges for Reprints in Euro (excl. VAT), prices are subject to change. Minimum order 50 copies.

\begin{tabular}{|c|c|c|c|c|c|c|}
\hline No. of pages & $\begin{array}{c}\mathbf{5 0} \\
\text { copies }\end{array}$ & $\begin{array}{c}100 \\
\text { copies }\end{array}$ & $\begin{array}{c}150 \\
\text { copies }\end{array}$ & $\begin{array}{c}200 \\
\text { copies }\end{array}$ & $\begin{array}{c}300 \\
\text { copies }\end{array}$ & $\begin{array}{c}500 \\
\text { copies }\end{array}$ \\
\hline $1-4$ & $345,-$ & $395,-$ & $425,-$ & $445,-$ & $548,-$ & $752,-$ \\
\hline $5-8$ & $490,-$ & $573,-$ & $608,-$ & $636,-$ & $784,-$ & $1077,-$ \\
\hline $9-12$ & $640,-$ & $739,-$ & $786,-$ & $824,-$ & $1016,-$ & $1396,-$ \\
\hline $13-16$ & $780,-$ & $900,-$ & $958,-$ & $1004,-$ & $1237,-$ & $1701,-$ \\
\hline 17-20 & $930,-$ & $1070,-$ & $1138,-$ & $1196,-$ & $1489,-$ & $2022,-$ \\
\hline $\begin{array}{l}\text { every additional } \\
4 \text { pages }\end{array}$ & $147,-$ & $169,-$ & $175,-$ & $188,-$ & $231,-$ & $315,-$ \\
\hline
\end{tabular}

Please send me send bill me for

no. of reprints

high-resolution PDF file (330 Euro excl. VAT)

E-mail address:

* Special Offer:

If you order 200 or more reprints you will get a PDF file for half price.

Please note: It is not permitted to present the PDF file on the internet or on company homepages.

Cover Posters (prices excl. VAT)

Posters of published covers are available in two sizes:

DinA2 42 × 60 cm / 17 x 24in (one copy: 39 Euro)

DinA1 $60 \times 84 \mathrm{~cm} / 24$ x 33in (one copy: 49 Euro)

Postage for shipping (prices excl. VAT)

overseas +25 Euro

within Europe +15 Euro
Editorial Office:

Wiley-VCH Verlag

Boschstraße 12

69469 Weinheim

Germany

Tel.: (+49) 6201606531

Fax: (+49) 6201606510

Email: advmattechnol@wiley-vch.de

Manuscript No.:

Customer No.: (if available)

Purchase Order No.:

Author:

Information regarding VAT: The charges for publication of cover pictures /reprints/issues/poster/Video abstracts/are considered to be "supply of services" and therefore subject to German VAT. However, if you are an institutional customer outside Germany, the tax can be waived if you provide us with the valid VAT number of your company. Non-EU customers may have a VAT number starting with "EU" instead of their country code, if they are registered with the EU tax authorities. If you do not have a valid EU VAT number and you are a taxable person doing business in a non-EU country, please provide a certification from your local tax authorities confirming that you are a taxable person under local tax law. Please note that the certification must confirm that you are a taxable person and are conducting an economic activity in your country. Note: certifications confirming that you are a taxexempt legal body (non-profit organization, public body, school, political party, etc.) in your country do not exempt you from paying German VAT.

VAT number:

Mail reprints / copies of the issue to:

Send bill to:

I will pay by bank transfer

I will pay by credit card

VISA, Mastercard and AMERICAN EXPRESS

For your security please use this link (Credit Card Token Generator) to create a secure code Credit Card Token and include this number in the form instead of the credit card data. Click here:

https://www.wiley-vch.de/editorial production/index.php

CREDIT CARD TOKEN NUMBER 